\title{
Morfodinâmica da desembocadura da Lagoa de Tramandaí (RS, Brasil)
}

\author{
Ana Fatima da SILVA ${ }^{1}$, Elírio E. TOLDO JR. ${ }^{2}$ \& Jair WESCHENFELDER ${ }^{2}$
}

1 Programa de Pós-graduação em Geociências, Universidade Federal do Rio Grande do Sul. Av. Bento Gonçalves, 9.500, CEP 91.540-000, Porto Alegre, Brasil (ana.oceano@gmail.com).

2 Centro de Estudos de Geologia Costeira e Oceânica, Universidade Federal do Rio Grande do Sul, Campus Agronomia, Av. Bento Gonçalves, 9.500, CEP 91.540-000, Porto Alegre, Brasil (toldo@ufrgs.br, jair.weschenfelder@ufrgs.br).

Recebido em 04/2016. Aceito para publicação em 12/2016.

Versão online publicada em 08/05/2017 (www.pesquisasemgeociencias.ufrgs.br)

\begin{abstract}
Resumo - A comunicação de corpos lagunares com o oceano ocorre através de canais de maré (tidal inlets), os quais constituem-se em importantes feições na troca de sedimentos. Algumas variáveis (prisma de maré, geometria do canal, etc.) controlam sua morfodinâmica e podem modificar sua posição geográfica. 0 conhecimento dos fatores que comandam sua estabilidade é de extrema relevância para gerenciar a costa e conservar o ambiente lagunar. Neste trabalho foi analisada a estabilidade da desembocadura da Lagoa de Tramandaí, com base em dados hidrodinâmicos, sedimentológicos e morfológicos integrados em uma análise espaço-temporal. A desembocadura desta laguna está localizada entre as praias de Tramandaí e Imbé (litoral norte do Rio Grande do Sul) e encontra-se fixada com apenas uma estrutura tipo guia-corrente ao longo da margem esquerda. A metodologia utilizada consistiu de levantamento batimétrico, técnicas de geoprocessamento e cálculos das relações empíricas de estabilidade. Os dados obtidos permitiram observar que anteriormente à fixação da margem esquerda do canal, a migração da desembocadura acompanhava a direção preferencial da deriva litorânea, para NE. A análise das relações de estabilidade física permitiu concluir que o canal apresentava forte instabilidade antes da obra de fixação da desembocadura. Após a obra do guia-corrente, a seção transversal mínima foi fixada e não existem registros de assoreamento.
\end{abstract}

Palavras-chave: laguna costeira, guia-corrente, estabilidade do canal de maré, dinâmica morfossedimentar.

\begin{abstract}
Morphodynamics of the Tramandaí Lagoon inLEt (RS, BraziL). The link of the lagoon bodies with the ocean occurs through of the inlets, which are also important ways to sediments exchange. The morphodynamics of this environment is controlled by a series of variables, such as tidal prism and channel geometry, amongst others. The interactions between these variables can cause a modification of the inlet geographical position. The knowledge of these parameters and interaction processes is extremely relevant for preservation and management of lagoon systems. This work analyzed the stability of the mouth of Tramandaí Lagoon, based on hydrodynamic, sedimentological and morphological data, integrated in a spatial and temporal analysis. The mouth of the lagoon is located between the beaches of Tramandaí and Imbé (north coast of Rio Grande do $\mathrm{Sul}$ ) and is fixed by a rip-rap structure along its left margin. The methodology applied in this analysis consisted of bathymetry measurements, geoprocessing techniques and calculation of the empirical stability relations. It was possible to note that prior to fixing the left margin of the channel, the mouth migrated to the NE following of the predominant littoral drift. The analysis of the relations of physical stability allowed to conclude that the channel presented strong instability before the work of fixing the mouth. After the construction of the rip-rap, the minimum transversal section of the inlet has been fixed and there are no silting records.
\end{abstract}

Keywords: coastal laguna, rip-rap, tidal inlet stability, morphossedimentary dynamic.

\section{Introdução}

Por sua beleza singular, a zona costeira serve de atrativo as pessoas que buscam desfrutar seus momentos de descanso ou que procuram fixar residência. Com isso, a ocupação desordenada degrada e descaracteriza esse ecossistema avan- çando sobre locais como dunas, áreas alagadas pela maré, manguezais, margens de rios, etc. Até o ano de 2011 , cerca de $27 \%$ da população brasileira estava concentrada em municípios da zona costeira, sem contar no verão, que em muitos locais a população fica até dez vezes maior (Strohaecker, 2007). No litoral norte do Rio Grande do Sul (RS) 
a intensificação de moradores ocorreu a partir dos anos 40, iniciada pelos pescadores que obtinham sua fonte de renda do oceano e das lagoas costeiras. Com o contínuo desenvolvimento desta antropização, ocorreram modificações ambientais nas praias, dunas e margens das desembocaduras, principalmente pela urbanização destes locais e, sem o conhecimento da dinâmica local, por naquele momento não se ter entendimento desta questão.

Desembocaduras (inlets) servem de comunicação entre os corpos de água interiores (lagunas, estuários e baías) e o oceano. Estes canais segmentam ilhas-barreiras, tanto transgressivas como regressivas, em duas ou mais porções (Hayes \& Fitzgerald, 2013), ao longo das zonas costeiras, sendo importantes feições na troca de sedimentos. Também, possuem extrema importância para o meio biótico, pois através dos canais ocorrem as trocas de nutrientes, propiciando o ciclo de vida nestas regiões. São locais intensamente utilizados para atividades sociais e econômicas, como o turismo, o lazer e a pesca.

As desembocaduras compreendem três regiões principais: (1) porção oceânica, que inclui o corpo sedimentar externo (delta de maré vazante); (2) o canal principal, correspondente à região com a mínima área de secção transversal; e, (3) a porção interna, com seu corpo sedimentar interno (delta de maré enchente) (Bruun, 1978). Hayes (1979) classificou as desembocaduras em cinco tipos diferentes de acordo com a amplitude da maré e a altura das ondas. Através de dados de 89 desembocaduras, Carr-Betts et al. (2012) demonstraram divergências da classificação proposta por Hayes (1979) afirmando que outros fatores controlam a morfologia dos inlets.

As desembocaduras podem ser consideradas sistemas morfodinâmicos, funcionando através da interação dos três componentes principais: dinâmica de fluidos, transporte de sedimentos e mudanças morfológicas (Cassiano \& Siegle, 2010). A morfodinâmica das desembocaduras é controlada pelas variáveis: prisma de maré, geometria do canal, energia das ondas e das marés, aporte sedimentar, distribuição dos canais estuarinos ou lagunares no reverso da barreira, estratigrafia regional, declive da antepraia e as modificações por obras de engenharia (Fitzgerald et al., 2001). Dentre os tipos de intervenções, esses autores citam principalmente a combinação de estruturas tais como molhes e obras de dragagem do canal.

As desembocaduras podem migrar ou permanecer em uma determinada posição dependendo das complexas interações entre o prisma de maré, energia de ondas, disponibilidade de sedimentos (U.S. Army, 2002) e a descarga fluvial (Siegle et al., 2004). Com esta ampla variação de fatores que influenciam na morfologia, e sendo que as desembocaduras exercem importante controle sobre o balanço sedimentar costeiro, não é inesperado que ocorram processos erosivos praiais, os quais podem estar associados às causas naturais ou antrópicas. Algumas desembocaduras são fixadas por estruturas rígidas como enrocamentos, molhes e guia-corrente; outras são livres e, portanto, sujeitas a migração de acordo com a dinâmica sedimentar local. A construção de portos e molhes podem causar fortes impactos que devem ser previstos no intuito de minimizar seus efeitos no transporte sedimentar (Soares, 2005). Segundo Jain et al. (2004) o conceito de estabilidade da desembocadura depende do potencial de equilíbrio entre a área da seção transversal da desembocadura e o volume de água e de sedimentos transportados.

As instalações de obras costeiras requerem estudos técnicos e ambientais prévios antes de serem executadas. Um preciso e detalhado projeto deve ser requisitado, para fins de minimizar os impactos sobre a dinâmica sedimentar do ambiente. 0 desenvolvimento de obras costeiras em águas rasas pode causar alterações principalmente relacionadas à deriva litorânea pela intervenção na migração dos sedimentos.

Por ser considerado o ambiente mais complexo da zona costeira (Komar, 1996), e por sua extrema importância, estudos com relação à morfologia das desembocaduras foram desenvolvidos ao longo dos anos, principalmente sobre novas técnicas para compreensão dos fatores controladores da estabilidade. As atividades antrópicas nestas regiões são crescentes, principalmente associadas a questões de ordem econômica, podendo gerar graves consequências ambientais e resultando até mesmo em riscos à própria população. $\mathrm{O}$ conhecimento e a manutenção da dinâmica natural destas regiões é um dos maiores desafios para os pesquisadores. Bruun \& Gerritsen (1960) observaram que a circulação pela maré tende a manter o canal, e a deriva litorânea de sedimentos tende a assorear a desembocadura. Sendo assim, a morfologia na desembocadura tenderá a se transformar continuamente refletindo o resultado do balanço de sedimentos que ocorre na região.

A desembocadura da Lagoa de Tramandaí (295' $30^{\prime \prime} \mathrm{S} / 50^{\circ} 07^{\prime} 00^{\prime \prime} \mathrm{W}$ ), localizada entre as praias de Tramandaí e Imbé, é uma das cinco que ocorrem no litoral do RS e encontra-se fixada com apenas uma estrutura tipo guia-corrente ao longo da margem esquerda. Os primeiros moradores 
a ocuparem esta região foram os pescadores que utilizavam o canal lagunar como acesso ao mar. Em determinados momentos na saída para o mar, se sentiam prejudicados por não terem o pretendido acesso, porque a desembocadura estava fechada, ou seja, assoreada por sedimentos arenosos. Sendo assim se reuniam em grupos e abriam o canal com enxadas e pás. Com o passar do tempo, advindo às tecnologias, o Departamento Estadual de Portos, Rios e Canais (DEPREC), hoje Superintendência de Portos e Hidrovias (SPH), construiu um guia-corrente em 1960 sobre a margem esquerda, para fixação do canal, impedindo sua migração e mantendo a profundidade (Motta, 1965; D'Aquino, 2004).

Na mesma década o Instituto de Pesquisas Hidráulicas (IPH-UFRGS) foi contratado para realizar estudos com o intuito de analisar as consequências de tal regularização. Foi então desenvolvida uma pesquisa em modelo físico reduzido, o qual mostrou como resultado que a construção de um par de molhes se estendendo até a isóbata de $5 \mathrm{~m}$, não manteria um canal de acesso com profundidade esperada de $4 \mathrm{~m}$. Além disso, a praia de Imbé ao norte da desembocadura sofreria um gradual e significativo recuo.

A fixação da margem esquerda da desembocadura favoreceu não só os pescadores, mas também a urbanização no município de Imbé, que se desenvolveu de forma intensa. As embarcações da PETROBRAS, que possui um terminal de operações marítimas dentro do canal, foram também favorecidas facilitando o acesso ao mar.

No presente trabalho, o objetivo é analisar a estabilidade da desembocadura da Lagoa de Tramandaí, com base em dados hidrodinâmicos, sedimentológicos e morfológicos integrados numa análise espaço-temporal. Mesmo com sua importância estratégica para o desenvolvimento socioeconômico da região, a dinâmica da desembocadura é pouco conhecida. Os resultados são relevantes para o adequado gerenciamento costeiro e a conservação do meio ambiente lagunar.

\section{2 Área, materiais e métodos}

\subsection{Caracterização geológica, climatológica e oceanográfica}

A desembocadura da Lagoa de Tramandaí, localizada na porção nordeste da planície costeira do $\mathrm{RS}$, serve como divisor político entre os municípios de Imbé, ao norte, e Tramandaí, ao sul (Fig. 1). 0 sistema lagunar é constituído pelas Lagoas de Tra- mandaí e Armazém, ambas inseridas no sistema de lagoas desta planície (Tabajara, 1994). A barreira costeira de idade holocênica na porção leste da área de estudo apresenta uma estratigrafia regressiva (progradante) (Travessas et al., 2005).

A água doce que ingressa na Lagoa de Tramandaí é proveniente principalmente do rio Tramandaí, que pertence à bacia hidrográfica de mesmo nome com área de $3.145 \mathrm{~km}^{2}$. 0 sistema do escoamento laguna-mar depende do regime pluviométrico regional, do maior ou menor represamento das águas pelos ventos do quadrante sul e da ocorrência das marés meteorológicas (Tabajara, 1994).

O clima na região é subtropical úmido, sendo que o litoral norte do RS é mais chuvoso e mais quente que o litoral sul. Segundo Nimer (1977), os ventos são controlados pelos sistemas de altas pressões tropicais e polares do Anticiclone Tropical do Atlântico Sul (ATAS) e do Anticiclone Polar Migratório (ATM) induzindo maior incidência dos ventos do quadrante nordeste entre os meses de setembro a março, e os ventos de sudoeste entre abril e agosto. A precipitação média na área de $1311,9 \mathrm{~mm}$ apresenta um pequeno aumento no inverno (Hasenack \& Ferraro, 1989).

De acordo com a classificação de Davies (1980), a costa do RS é do tipo micromarés, caracterizada por marés astronômicas inferiores a $2 \mathrm{~m}$, com amplitude média de $0,25 \mathrm{~m}$, sendo que a maré meteorológica pode alcançar 1,20 m (Almeida et al., 1997).

Incidem sobre a costa do Rio Grande do Sul ondulações geradas no oceano Atlântico sul e vagas geradas pelos fortes ventos locais de verão e primavera, provenientes de NE. Exceto pela passagem das frentes frias de S e SE, a agitação marítima é caracterizada por ondas de média a elevada energia, com altura significativa de $1,5 \mathrm{~m}$ e período entre 7 e 9 s (Almeida et al., 1997). Consequentemente, o transporte e a deposição dos sedimentos ao longo da costa são primariamente dominados pela ação das ondas.

Os sedimentos do sistema praial adjacente a desembocadura são constituídos por areias finas bem selecionadas $(\mathrm{Mz}=0.2 \mathrm{~mm}$ ) (Toldo Jr. et al., 1993). Os depósitos de areia são abundantes no litoral e plataforma continental interna do Rio Grande do Sul sendo intensamente transportados pelo vento e pelas ondas.

As fortes correntes litorâneas exibem um comportamento episódico, tendo como importante forçante as ondulações provenientes do quadrante sul, principalmente aquelas relacionadas a passagem de frentes frias nos períodos de inverno. 


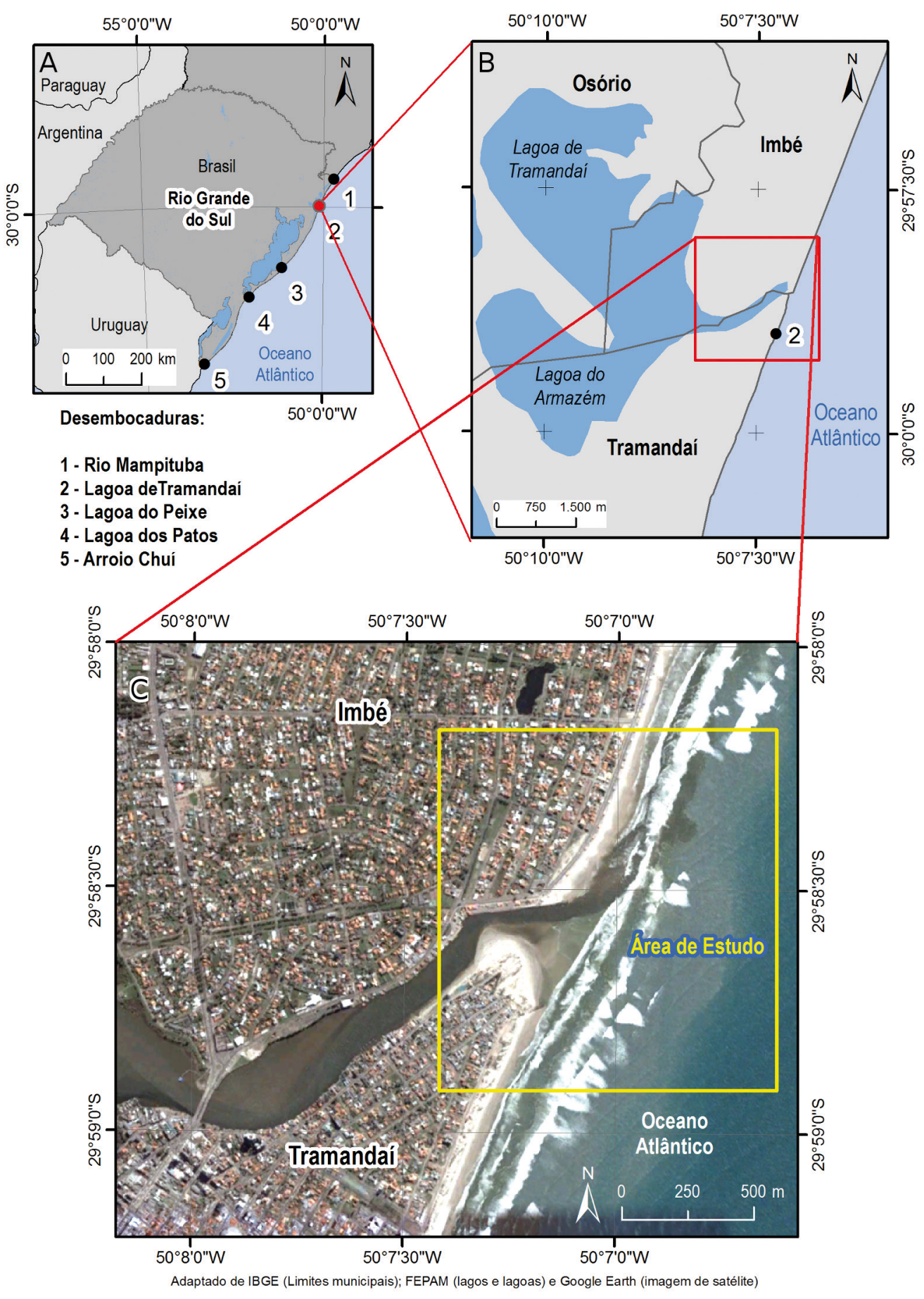

Figura 1. Área de estudo. A) Localização das desembocaduras litorâneas no estado do Rio Grande do Sul; B) Delimitação da desembocadura da Lagoa de Tramandaí, situada entre os municípios de Imbé ao norte e Tramandaí ao sul; C) Canal lagunar em destaque, onde o alinhamento ao longo da margem esquerda corresponde ao guia-corrente.

Figure 1. Study area. A) Rio Grande do Sul inlet locations; B) Demarcation of the Tramandaí Lagoon inlet, situated between the municipalities of Imbé to the North, and Tramandaí to the South; C) Lagoon channel highlighted, where the line along the left margin corresponds to the rip-rap.

Ondas com ângulo de incidência de $10^{\circ}$ e altura de $1,79 \mathrm{~m}$, geram correntes que atingem velocidades da ordem de $0,9 \mathrm{~m} / \mathrm{s}$ (Toldo Jr. et al., 1993; Toldo Jr. et al., 2006). Segundo Jung \& Toldo Jr. (2011), as correntes litorâneas com direções para NE são dominantes, com velocidades variando entre 0,10 e $0,83 \mathrm{~m} / \mathrm{s}$. As correntes de maré no canal lagunar com vazões entre 75 e $200 \mathrm{~m}^{3} / \mathrm{s}$ e média de 130 $\mathrm{m}^{3}$ / s (Motta, 1965, 1967), apresentam baixa influência na sedimentação e morfogênese costeira, as quais impedem que a desembocadura seja obstruída pelo assoreamento sedimentar.

O sentido preferencial do transporte sedimentar em frente a desembocadura é para nordeste, com a migração da desembocadura neste sentido. Este comportamento foi observado por 
Tomazelli \& Villwock (1992), a partir da interpretação de aerofotos dos anos de 1948 a 1975. Simulações matemáticas da deriva litorânea foram efetuadas por Lima et al. (2001), com emprego do método do fluxo de energia (U.S. Army, 1984), encontrando valores líquidos para região na ordem de $1.520 .130 \mathrm{~m}^{3} /$ ano $(\mathrm{K}=0,64)$ e $926.329 \mathrm{~m}^{3} /$ ano $(\mathrm{K}=0,39)$ e direção resultante para nordeste. Com a divisão do litoral médio em células litorâneas, Motta (2011) quantificou a deriva litorânea, através do mesmo método, obtendo para célula 12 (região mais próxima da desembocadura da Lagoa de Tramandaí) o valor de $2.322 .470 \mathrm{~m}^{3}$, entre os anos de 1998 e 2009.

\subsection{Materiais e métodos}

\subsubsection{Aquisição dos dados}

Para o reconhecimento do fundo na área da desembocadura foi conduzido um levantamento batimétrico. A metodologia utilizada consistiu na utilização da ecossonda Humminbird 987C SI Combo com sensor de $200 \mathrm{kHz}$. As linhas de sondagem foram estabelecidas de modo paralelo e perpendicular à linha de praia com espaçamento médio de $200 \mathrm{~m}$. A correção de nível foi conduzida com uma régua linimétrica situada na desembocadura da Lagoa de Tramandaí e adicionalmente com maregramas de Rio Grande. Posteriormente, as isóbatas foram geradas através do método de interpolação por triangulação.

\subsubsection{Geoprocessamento}

As fotografias aéreas utilizadas correspondem a levantamentos realizados em 1940, 1942, $1948,1953,1964,1967,1970,1974,1986$, e as imagens de satélite dos anos 2005, 2010 e 2012 foram adquiridas no Google Earth ${ }^{\circledR}$. 0 processo de georreferenciamento das fotografias aéreas e das imagens Google Earth foram executadas no software ArcMAP e ArcGis 10.

0 registro da imagem mais recente Google Earth $®$ de 2012 se deu a partir de uma imagem do satélite LANDSAT-7, sensor ETM+, ortorretificada e com resolução espacial de 15 m; por aplicação da rotina de geoprocessamento que executa a fusão de imagens multiespectral e pancromática, através do software ENVI. Foram estabelecidos seis pontos de controle e, a partir da imagem georreferenciada do Google Earth $\AA$, foram registradas todas as demais imagens da área, desde 1940 até 2010, com seis pontos de controle equivalentes.
2.2.3 Cálculos das relações empíricas de estabilidade

As amplitudes de maré de sizígia e de quadratura foram estimadas a partir da Tábua de Marés para o porto de Rio Grande disponibilizada pela Diretoria de Hidrografia e Navegação (DHN). A área da Lagoa de Tramandaí foi medida a partir das imagens de satélite georreferenciadas.

0 prisma de maré foi calculado utilizando a equação 1 :

$$
P=A_{m} \cdot A
$$

onde $A_{m}$ é a amplitude da maré ( $\left.m\right)$, A é a área da laguna $\left(\mathrm{m}^{2}\right)$.

Primeiramente a área da seção transversal do canal foi calculada a partir das fórmulas propostas por O'Brien (1969) (Equação 2) e Jarret (1976) (Equação 3)

$$
\begin{aligned}
& \left.A=\left(9,02 \times 10^{-4}\right) \times P^{0,85}\right) \\
& \left.A=\left(1,57 \times 10^{-4}\right) \times P^{0,95}\right)
\end{aligned}
$$

onde A é a área da seção transversal mínima $\left(\mathrm{m}^{2}\right)$ e P é o prisma de maré $\left(\mathrm{m}^{3}\right)$.

Após coleta de dados batimétricos da área do canal foi possível à realização do cálculo da área da seção transversal utilizando o software SURFER (Golden Software).

A relação largura e profundidade foi calculada a partir da equação 4 :

$$
L / D_{m}
$$

onde L é a largura da seção mínima do canal (m) e $\mathrm{D}_{\mathrm{m}}$ é a profundidade média do canal (m).

Outra relação de estabilidade aplicada foi aquela proposta por Bruun \& Gerritsen (1960), relacionando o transporte de sedimentos litorâneos total $\left(\mathrm{M}_{\mathrm{t}}\right)$ com o prisma de maré de sizígia $(\mathrm{P})$, representando deste modo a capacidade dos fluxos de enchente e vazante de maré em transportarem os sedimentos depositados no canal (Siegle, 1999).

\section{Resultados e discussão}

\subsection{Morfometria do canal lagunar}

A partir da coleção de fotografias aéreas foram obtidas as extensões de superfície média do canal e da laguna, num total de $18,27 \mathrm{~km}^{2}$, valor que pode variar em função da influência das precipitações pluviométricas sobre o nível médio das águas. 0 corpo lagunar é raso (Fig. 1), sendo que a Lagoa do Armazém apresenta valores entre 0,5 e 1 m e, a Lagoa de Tramandaí possui um máximo de $1,40 \mathrm{~m}$ de profundidade. 
A extensão do canal de Tramandaí é de 1,5 km e nas proximidades da seção transversal mínima (Fig. 2) a largura é de $55 \mathrm{~m}$ e profundidade média de 2,90 m. Estas dimensões são controladas pelas condições geológicas do terreno, meteorológicas e hidrodinâmicas e apresentam pequenas variações, principalmente por causa da reduzida amplitude da maré. Apesar da margem esquerda do canal estar fixada, a margem direita é livre e se desenvolve sobre um pontal arenoso que cresce para norte, e força o fechamento do canal. Mesmo sendo uma desembocadura estabilizada pela construção do guia-corrente, são observadas pequenas variações batimétricas no canal, controladas pela morfodinâmica do pontal.

O fundo do canal lagunar é composto por areias finas, cuja deposição resulta da ação de correntes bidirecionais controladas pelas marés (Tabajara, 1994). Com o avanço da urbanização em direção às desembocaduras ou com a construção de estruturas de fixação há certa tendência em ocorrer o estrangulamento da área da seção mínima do canal. Entretanto, ao observarmos a tendência de migração do canal com base nas fotografias aéreas se observa que a área da seção transversal do canal se conserva durante este processo.

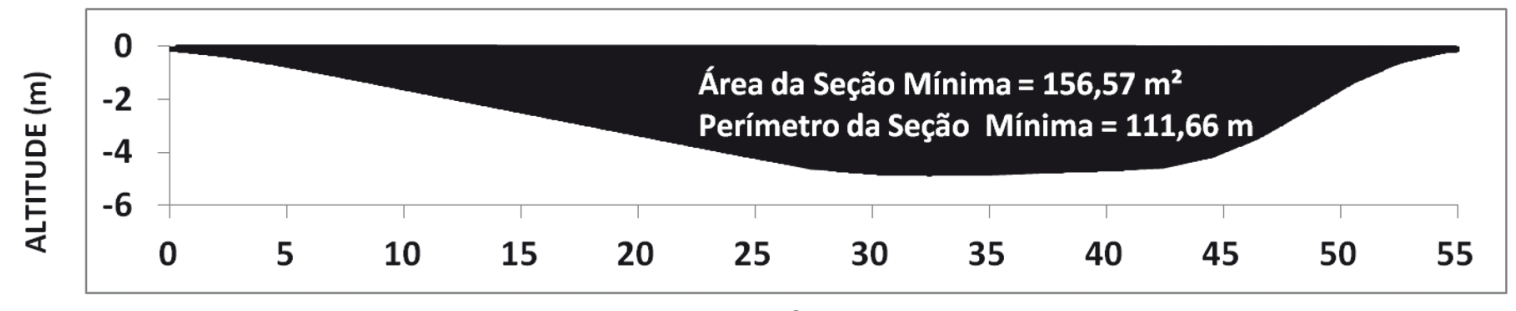

DISTÂNCIA (m)

Figura 2. Perfil da seção transversal mínima do canal lagunar. Figure 2. Minimum cross-sectional profile of the lagoon channel.

Num estudo realizado sobre os mecanismos que contribuem para o assoreamento de canais, Pope (2000) descreve padrões associados com estes mecanismos. Ao discutir sobre a migração de um canal, o autor afirma que a área da secção transversal é aproximadamente conservada durante a migração e, se a margem submetida à erosão encontrar uma superfície resistente, como um molhe, o canal pode aprofundar e estreitar-se, mas mantendo a capacidade de acomodar o mesmo escoamento hidráulico.

\subsection{Histórico da migração do canal}

Os resultados das mudanças morfológicas na desembocadura da Lagoa de Tramandaí, desde a década de 40 até os dias atuais podem ser obtidos a partir das fotografias e imagens aéreas (Figs. 3 a 5). No momento em que houve a construção do guia-corrente na margem esquerda em 1961 o canal se tornou estável, porém, a margem direita submetida à dinâmica do pontal arenoso possui forma variável, controlada pelo tamanho e orientação do pontal.

A região da desembocadura da laguna na década de 40 apresentava uma conformação bastante diferenciada, havia poucas residências habitadas por pescadores.

A desembocadura se encontrava em uma posição similar aos dias atuais, migrando livremen- te para NE, acompanhando a direção preferencial da deriva litorânea. Em 1940 se observa um canal abandonado orientado paralelamente à linha de costa (Fig. 4A), protegido pelo pontal arenoso. Nesta época não é possível afirmar que o canal rompeu a barreira arenosa naturalmente, pois se têm relato que foram feitas intervenções de aberturas pelos pescadores em 1937.

Nesta figura (Fig. 4A) também se observa o tipo de praia adjacente à desembocadura através do número de linhas de espuma, as quais estão associadas à quebra das ondas indicando presença de mais de um banco arenoso submerso, conferindo à praia características dissipativas do tipo banca e cava longitudinal (Jung \& Toldo Jr., 2011).

Em 1942 o referido canal abandonado citado é reativado provavelmente pela obstrução da desembocadura causada pela deriva litorânea, de modo que o, seu novo posicionamento dista $0,9 \mathrm{~km}$ para nordeste. Também, a migração da desembocadura modifica a posição da seção mínima. Ainda, é possível visualizar o avanço dos campos de dunas sobre o pontal arenoso. 0 transporte eólico se constitui no principal mecanismo de assoreamento do canal lagunar quando este for abandonado (Fig. 4DE).

No ano de 1948 a desembocadura retorna a posição mais ao sul, porém trata-se de abertura artificial por ação antrópica. Os sedimentos depositados na desembocadura são carreados para o oceano estando disponibilizados para retrabalha- 
mento e transporte pelas correntes litorâneas. A ocupação na margem esquerda começa a se potencializar com a construção do loteamento Praia de Imbé, cuja comercialização dos lotes teve início em 1941 (Claussen \& Strohaecker, 2015).

Em 1953 o terreno úmido ao longo do canal abandonado se apresenta ocupado. Um movimento lateral do canal é notado em decorrência do meandramento natural induzido pelo crescimento do pontal arenoso, para norte. No lado sul do canal se desenvolve um baixio, enquanto que no lado norte se observa um talvegue com gradiente mais acentuado por causa da erosão sobre a margem esquerda, que resulta em um perfil transversal nos moldes da seção mínima ilustrada na figura 2. Este mecanismo de migração se assemelha ao descrito e classificado por Pope (2000) quando estudou padrões de canais em geral, e pode ser utilizado para descrever a dinâmica e a evolução morfológica desta desembocadura, conforme descrito anteriormente.

As fotografias aéreas de 1964 e 1967 mostram a instalação e o posicionamento da obra de engenharia costeira que resultou na fixação da margem esquerda, no isolamento físico do canal abandonado e a formação de uma área denominada pelos moradores como "braço morto", isto é, uma porção residual do canal abandonado que ainda está preservada.

Nos anos subsequentes a ocupação se intensifica, principalmente com a construção da Estrada Interpraias (RS-786) que favorece o crescimento urbano nos municípios de Imbé e Tramandaí para ocupação de segunda residência (Claussen \& Strohaecker, 2015). Um calçadão sobre o campo de dunas é construído e algumas áreas úmidas são aterradas. É visível a redução do campo de dunas e a mobilidade da margem direita por não estar fixada (Fig. 5).

Através da comparação das fotografias e imagens apresentadas nas figuras 4 e 5 é possível comentar que houve uma enorme transformação no ambiente natural. 0 pacote sedimentar do esporão arenoso aumentou cerca de $150 \mathrm{~m}$ em direção ao norte $(1940 ; 2012)$ e, um recuo de $228 \mathrm{~m}$ ocorreu na margem esquerda da desembocadura (1953; 1974).

O padrão morfodinâmico da desembocadura da Lagoa de Tramandaí anterior à fixação é o mesmo encontrado na região (Araújo, 2008; Vieira da Silva et al., 2011; Schossler, 2011), ou seja, a intensa migração da desembocadura forçada pelo crescimento de um pontal arenoso no sentido da deriva litorânea predominante e a redução da seção transversal mínima (Fitzgerald, 1996). A de- riva litorânea ocorre em ambos os lados do inlet, sendo assim os sedimentos arenosos não são barrados pela estrutura fixa justamente por esta não ultrapassar a zona de arrebentação (Lélis \& Calliari, 2004).

\subsection{Relações de estabilidade}

O comportamento morfodinâmico e a estabilidade da desembocadura e zonas costeiras adjacentes são governados por uma complexa interação entre as ondas, o fluxo das marés, a descarga fluvial e o transporte de sedimentos (Fitzgerald, 2005). A tendência é que o fluxo das marés remova os sedimentos depositados no canal e que a deriva litorânea obstrua o canal pela deposição sedimen$\operatorname{tar}$ (Bruun \& Gerritsen, 1960). Todas as interações que ocorrem entre a dinâmica do prisma de maré, transporte e deposição, incidência das ondas e a variabilidade da amplitude da maré causam mudanças na morfologia do canal.

$\mathrm{O}$ valor calculado para o prisma de maré em condições de sizígia foi de $6.759 .900 \mathrm{~m}^{3}$. A altura da maré de quadratura é muito similar, sendo, portanto os cálculos efetuados apenas na maré de sizígia. A partir da utilização dos coeficientes propostos por Jarret (1976), os valores encontrados para área de seção transversal foi de 459,55 m². Através dos coeficientes propostos por O'Brien (1969), o valor encontrado foi de 576,31 $\mathrm{m}^{2}$ e, empregando o levantamento batimétrico a área da seção transversal apresentou como resultado 156,57 $\mathrm{m}^{2}$.

De acordo com Stive \& Rackhorst (2008), as relações empíricas utilizadas no cálculo das áreas transversais de equilíbrio acabam por apresentar valores maiores do que os encontrados na natureza. Em desembocaduras de menor tamanho isto indica que a relação entre o prisma de maré e a área da secção transversal depende de parâmetros físicos adicionais, tais como período das marés, largura do canal e velocidade da deriva litorânea bruta ao longo da costa como indicado por Kraus (1998).

Como se sabe o prisma de maré aumenta conforme aumenta a área da laguna ou a amplitude da maré. 0 prisma se mantendo constante tende a manter a área da seção transversal constante. No caso da desembocadura em estudo se o prisma aumentar, a área da seção transversal aumentará, porém apenas a margem direita do canal sofrerá alterações em sua morfologia. Se o prisma diminuir de amplitude a área da seção transversal também tenderá a diminuir. Se a área da baía ou laguna localizada na retrobarreira for de pequena dimensão a área da seção transversal do canal será 


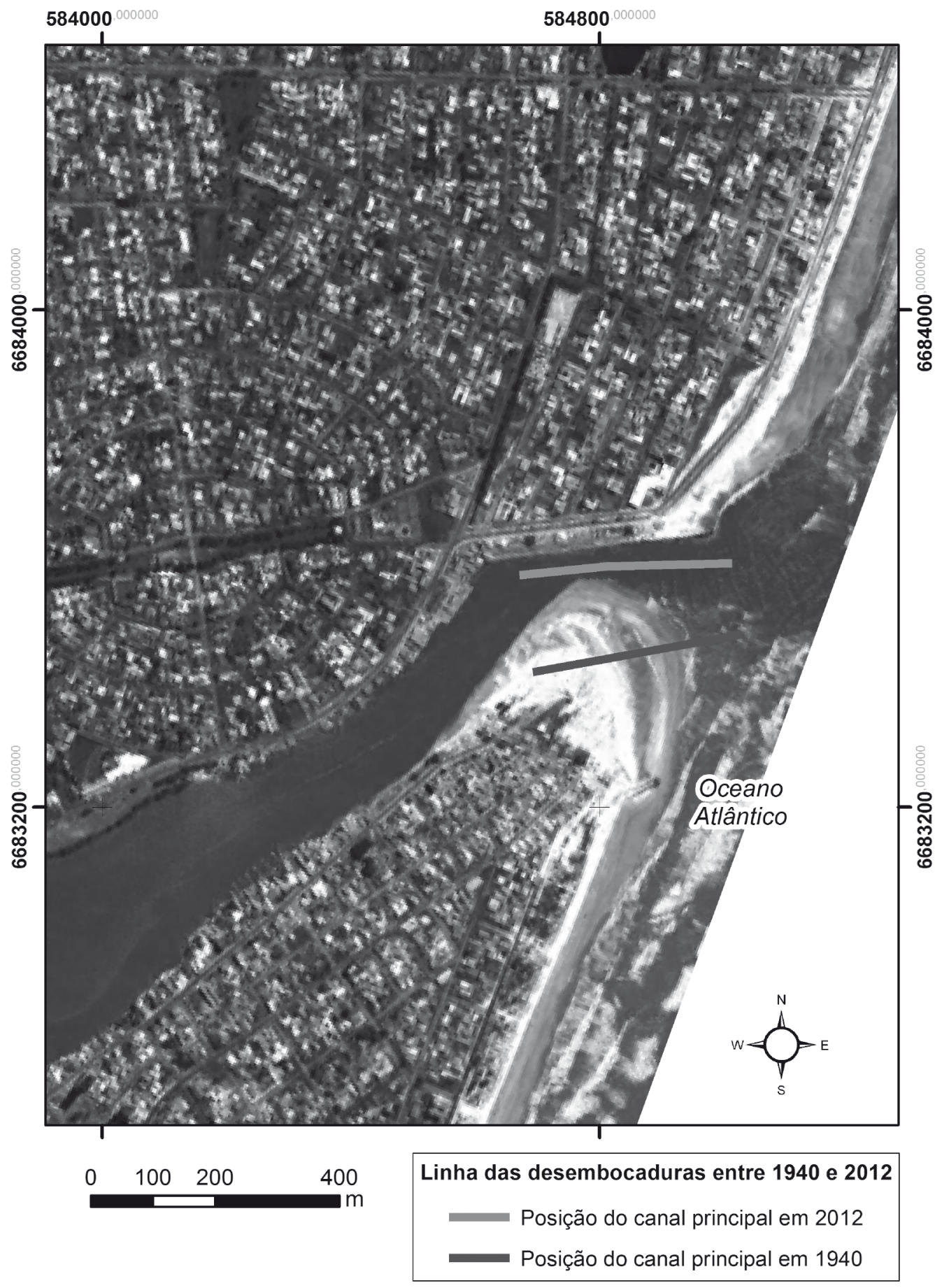

Figura 3. Linhas representativas da posição do canal da desembocadura em 1940 e 2012.

Figure 3. Lines representing the position of the channel of the inlet in 1940 and 2012.

reduzida, bem como o prisma de maré. Aumentando a dimensão do corpo lagunar, ou da baía os demais fatores também sofrerão um aumento (Hayes \& Fitzgerald, 2013). Na área em estudo, a partir da fixação da desembocadura a área mínima da seção transversal se manteve estável, por não ocorrerem modificações no prisma de maré.

A abertura ou fechamento da desembocadura, bem como a migração do canal são controlados pelas variáveis relacionadas anteriormente. A deriva litorânea atua forçando o fechamento da desembocadura, e em oposição, os escoamentos laguna- res controlados pela precipitação na bacia do Rio Tramandaí e, também, o prisma de maré forçam a abertura e a manutenção da desembocadura.

De acordo com Fitzgerald (2005), a deriva litorânea deposita sedimentos no interior do canal e, dependendo do ciclo de maré, esse sedimento é levado em direção ao mar e/ou em direção à laguna, formando os deltas em ambas as extremidades. Em um lado do canal ocorre a deposição de sedimentos enquanto no lado oposto ocorre erosão, ou seja, o canal migra de acordo com a direção do transporte predominante ao mesmo tempo em 

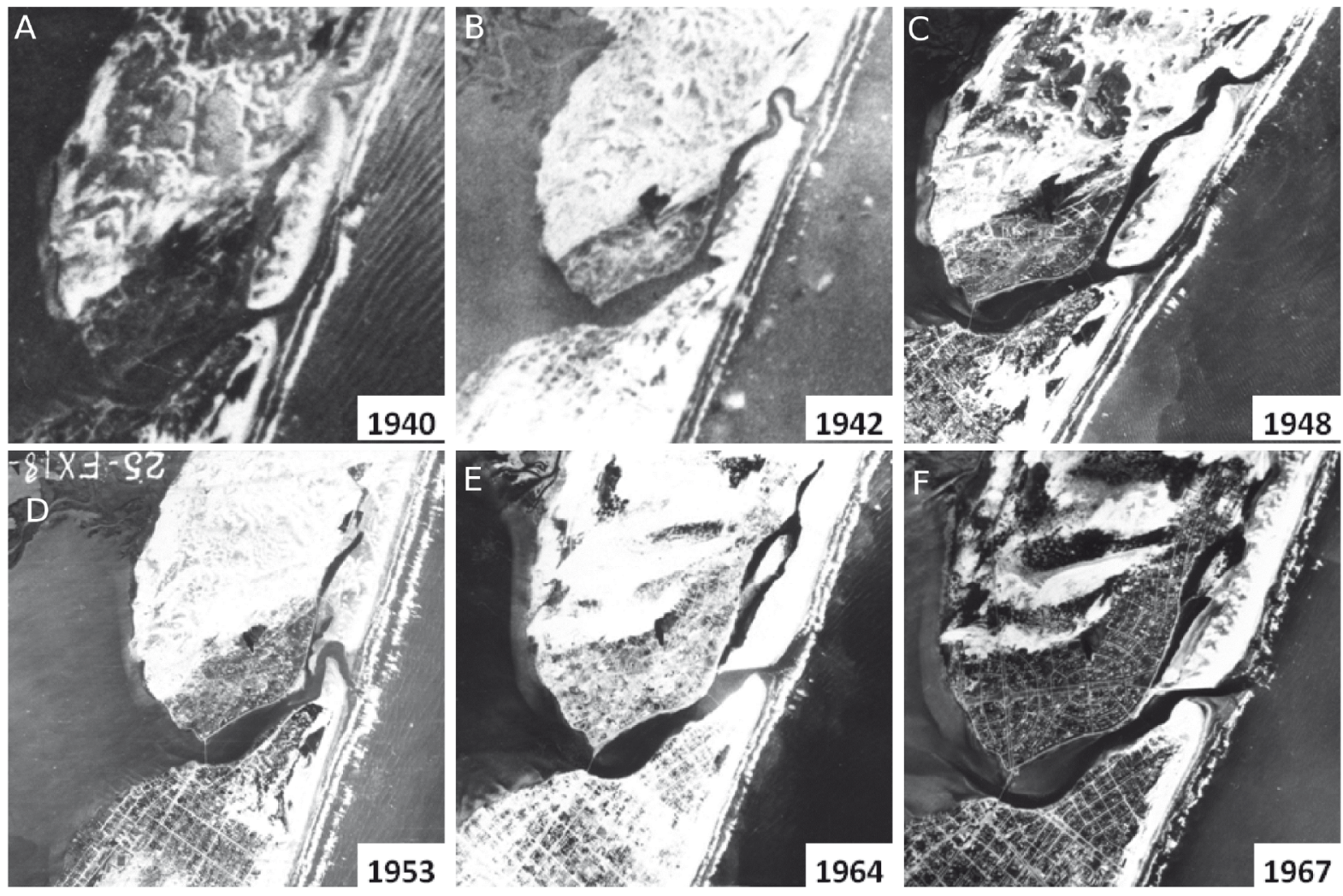

Figura 4. Coleção de fotografias aéreas do canal e desembocadura lagunar entre 1940 e 1967, ilustrando a mobilidade desta feição. A) Início do processo de urbanização na década de 40; B) Novo posicionamento da desembocadura (migração para nordeste); C) Retorno da posição da desembocadura mais para sul; D) Assoreamento do canal lagunar abandonado; E) Instalação do guia-corrente no início dos anos 60; F) Porção residual do canal abandonado.

Figure 4. Collection of aerial fotographies of the lagoon channel and inlet between 1940 and 1967, ilustrating the mobility of the features. A) Beginning of urbanization in the 1940's; B) New positioning of the mouth (migration to the northeast); C) Return from the position of the southern mouth; D) Sedimentation of the abandoned lagoon channel; E) Installation of the rip-rap in the early 1960 's; F) Residual portion of the abandoned canal .

que ocorre a tendência de manter a área do canal (Davis Jr. \& Fitzgerald, 2004).

Os bancos que se formam em frente à desembocadura ou o delta de maré vazante, atuam como um depósito regulador de sedimentos para alimentar as praias adjacentes. Motta (1967) cita que ocorre essa formação devido às tendências opostas do transporte litorâneo e dos escoamentos fluviais. Dependendo da direção do transporte predominante na área ocorrerá a migração lateral da desembocadura. Sendo assim, essa disponibilidade de sedimentos na porção exterior ao canal condicionará a relação entre o prisma de maré e a deriva litorânea (Siegle, 1999).

A partir dos dados de transporte de sedimentos medidos por Motta (2011), o valor encontrado para relação entre o prisma e a deriva litorânea foi de 22,03. Para Bruun \& Gerritsen (1960), uma desembocadura com valores $20<\mathrm{P} / \mathrm{Mt}<50$ significa uma desembocadura do tipo transpasse de banco, com arrebentação de ondas no banco durante tempestade. Ela permanece aberta, mas os sedimentos do canal só são retirados na época das chuvas com maior intensidade e é perigoso à navegação.

Para Kraus (2000), este valor encontrado classifica o canal como instável, com tendência ao assoreamento e/ou migração forçada pela deriva litorânea. Isso nos mostra que se a margem esquerda do canal em estudo não estivesse fixada, a desembocadura continuaria naturalmente migrando, transpassaria sedimento de um lado para outro bem como agregaria sedimento proveniente dos bancos do delta de maré vazante. 0 prisma de maré ocorrendo de forma estável, sendo responsável por uma constante remoção de sedimentos, condiciona ao não fechamento do canal, impedindo então a obstrução causada pela deriva litorânea.

A relação entre a largura (L) e a profundidade média $\left(D_{m}\right)$ da seção transversal mínima resultou em um valor de 19 para o canal lagunar. Quando a largura do canal aumenta devido a um evento meteorológico, o valor da relação também aumenta. Quando o valor encontrado for baixo, como neste caso, estará representando um canal estável. 

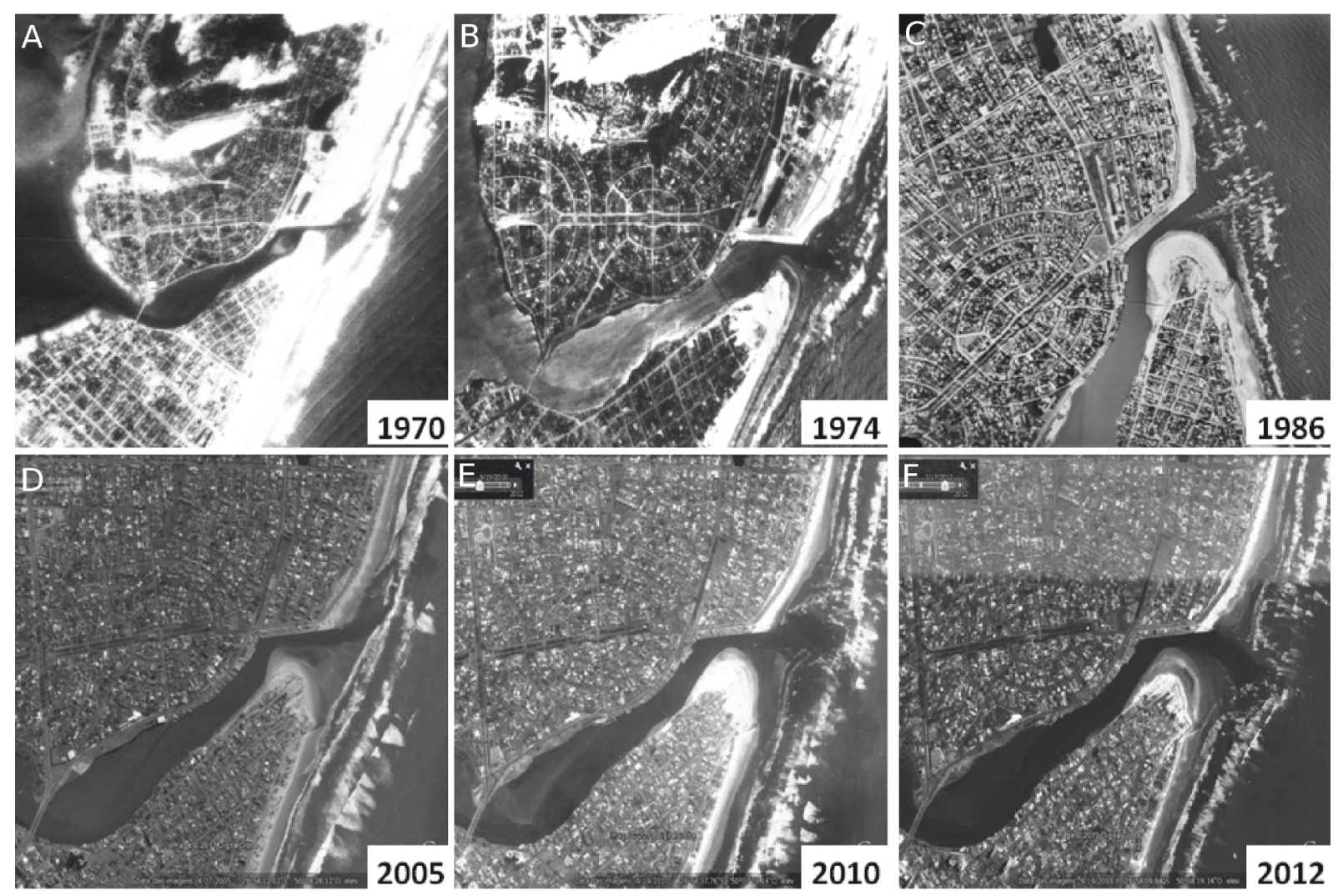

Figura 5. Fotografias aéreas e imagens entre 1970 e 2012, onde se observa o acelerado processo de urbanização. A) Aterramento do canal abandonado; B) Expansão da área urbana em Tramandaí e Imbé; C) Ocupação antrópica estabelecida sobre o campo de dunas; D, E e F) Reduzida mobilidade do pontal arenoso na extremidade norte da praia de Tramandaí.

Figure 5. Aerial fotographies and images of the period between 1970 and 2012, where rapid urbanization can be seen. A) Filling of the abandoned channel; B) Expansion of the urban area in Tramandaí and Imbé; C) Established anthropic occupation on the dune field; D, E e F) Reduced mobility of the sandy spit at the north extremity of the Tramandaí beach.

\subsection{Utilidade da obra costeira}

Para concretização de obras costeiras são necessários conhecimentos sobre a dinâmica do ambiente, tais como: ondas, correntes, ventos, marés, precipitação, etc. Se a instalação da obra ocorre sem uma boa base destes dados pode gerar problemas nas áreas adjacentes. Assim sendo, observando-se o atual momento em que se encontra o guia-corrente e com base em trabalhos na área de estudo sobre a linha de costa (Toldo Jr. et al., 1999; Lopes et al., 2008) se pode afirmar que o guia-corrente não afetou o transporte litorâneo que ocorre na região.

A praia de Imbé se mantém constante, apenas erodindo nos períodos de inverno (Toldo Jr., 1993; Weschenfelder \& Ayup-Zouain, 2002). Lélis \& Calliari (2004) encontraram taxas de erosão na linha de praia de Tramandaí e relacionaram este resultado com a intensa ocupação desordenada situada sobre as dunas frontais.

0 guia-corrente é eficiente no que diz respeito ao impedimento da migração da desembocadura, um dos motivos pelo qual foi construído. A questão de manter a profundidade em torno de $4 \mathrm{~m}$, como o esperado, não é sempre mantida, pois o esporão arenoso no lado direito do canal migra para norte e obstrui o canal, bem como o delta de maré vazante localizado em frente também fornece sedimentos para dentro do canal. Esta migração e oferta de sedimentos estão de acordo com registros observados em outras desembocaduras na região (Piérri, 2005; Araújo, 2008; Vieira da Silva et al., 2011).

Os pescadores que utilizam a desembocadura, bem como as embarcações da PETROBRÁS foram beneficiados com a obra podendo navegar seguramente. Apenas quando há períodos de grande deposição de sedimentos em frente à desembocadura a navegação fica comprometida devido à formação do banco de maré vazante. Não há proteção às ondas de maior energia para as embarcações saírem em alto mar, pois o guia-corrente não apresenta a mesma função dos molhes.

\section{Conclusões}

Na área de estudo o transporte sedimentar litorâneo mantém a tendência histórica e natural de obstruir a desembocadura, e induzir a sua migração para o lado norte, porém o reduzido prisma de 
maré exerce uma força suficiente e contrária para manter o canal desobstruído, sem os depósitos de areia do delta de maré vazante ou de enchente no seu interior.

A desembocadura lagunar teve transformações naturais e antrópicas, condicionadas principalmente aos fatores naturais, tais como: prisma de maré, regime de precipitação, incidência das ondas e transporte de sedimentos. Entretanto, após a fixação da margem esquerda cessaram as migrações do canal para NE, foi fixada a seção transversal mínima e não existem registros de assoreamento na desembocadura.

A margem direita do canal é livre e se desenvolve sobre um pontal arenoso que cresce para norte forçando o fechamento do canal e cuja morfodinâmica favorece pequenas variações batimétricas no canal.

A análise das relações de estabilidade física da desembocadura permite concluir que o canal apresentava forte instabilidade antes da construção do guia-corrente, em 1961.

0 guia-corrente instalado na desembocadura da Lagoa de Tramandaí, para a finalidade em que foi construído, foi eficiente quanto à ausência de impactos sobre a deriva litorânea, e principalmente quanto à estabilização da desembocadura.

\section{Referências}

Almeida, L.E.S.B., Rosauro, N.M.L. \& Toldo Jr., E.E. 1997. Análise Preliminar das Marés na Barra do Rio Tramandaí, RS. In: SIMPÓSIO BRASILEIRO DE RECURSOS HÍDRICOS, 12., 1997, Vitória. Anais... Vitória, ABRH, v.1, p. 7.

Araújo, R.S. 2008. Morfologia do Perfil Praial, Sedimentologia e Evolução Histórica da Linha de Costa das Praias da Enseada do Itapocorói - SC. Itajaí, 145p. Dissertação de Mestrado, Programa de Pós-graduação em Ciência e Tecnologia Ambiental, Universidade do Vale do Itajaí.

Bruun, P. 1978. Stability of coastal inlets - Theory and Engineering. Amsterdam, Elsevier, 510p.

Bruun, P. \& Gerritsen, F. 1960. Stability of Coastal Inlets. Amsterdam, North Holland, 123p.

Carr-Betts, E., Beck, T.M. \& Kraus, N.C. 2012. Tidal Inlet Morphology Classification and Empirical Determination of Seaward and Down-Drift Extents of Tidal Inlets. Journal of Coastal Research, 28(3): 547-556.

Cassiano, G.F. \& Siegle, E. 2010. Migração lateral da desembocadura do rio Itapocú, SC, Brasil: evolução morfológica e condicionantes físicas. Revista Brasileira de Geofísica, 28(4): 537-549.

Claussen, M.R.S. \& Strohaecker, T.M. 2015. O fechamento do Braço Morto (Rio Tramandaí) no município de Imbé. In: CONGRESSO DA ASSOCIAÇÃO BRASILEIRA DE ESTUDOS DO QUATERNÁRIO, 15., 2015, Imbé. Anais... Imbé, ABEQUA, v.1, p. 329-330.
D’Aquino, C.A. 2004. Calibração e Aplicação do Modelo Numérico Genesis nas praias de Tramandaí e Imbé, RS. Porto Alegre, 101p. Dissertação de Mestrado, Programa de Pós-graduação em Geociências, Instituto de Geociências, Universidade Federal do Rio Grande do Sul.

Davies, J.L. 1980. Geographical Variation in Coastal Development. Longman, Londres, 212p.

Davis Jr., R.A. \& Fitzgerald, D.M. 2004. Beaches and Coasts. Blackwell, Oxford, 419p.

Fitzgerald, D.M. 1996. Geomorphic variability and morphologic and sedimentologic controls on tidal inlets. Journal of Coastal Research, 23: 47-71.

Fitzgerald, D.M. 2005. Tidal Inlets. In: Schwartz, M.L. (Ed.). Encyclopedia of Coastal Science. Dordrencht, Springer, p. 958-965.

Fitzgerald, D.M., Kraus, N.C. \& Hands, E.B. 2001. Natural mechanics of sediment bypassing at tidal inlets. ERDC/CHL CHETN-IV-30. U.S. Army Corps of Engineers, $10 p$.

Hasenack, H. \& Ferraro, L. 1989. Considerações Sobre o Clima da Região de Tramandaí, RS. Pesquisas em Geociências, 22: 53-70.

Hayes, M.O. 1979. General morphology and sediment patterns in tidal inlets. Sedimentary Geology, S.l., 26: 139-156.

Hayes, M.O. \& Fitzgerald, D.M. 2013. Origin, Evolution, and Classification of Tidal Inlets. Journal of Coastal Research, 69: 14-33.

Jain, M., Mehta, A.J., Van de Kreeke, J. \& Dombrowski, M.R. 2004. Journal Observations on the Stability St. Andrew Bay Inlets in Florida. Journal of Coastal Research, 3(20): 913-919.

Jarret, J.T. 1976. Tidal prism-inlet area relationships. GITI Report n. 3, U.S. Army Corps of Engineers, Waterways Experiment Station, Vicksburg, Mississippi, $54 \mathrm{p}$.

Jung, G.B. \& Toldo Jr., E.E. 2011. Análise qualitativa da direção da corrente longitudinal entre 2004 e 2008 na praia de Tramandaí, RS, Brasil. Revista Brasileira de Geomorfologia, 13(1): 51-56.

Komar, P.D. 1996. Tidal-Inlet Processes and Morphology Related to the Transport of Sediments. Journal of Coastal Research, 23: 23-45.

Kraus, N.C. 1998. Inlet cross-sectional area calculated by process-based model. Coastal Engineering Proceeding, 26: 3265-3278.

Kraus, N.C. 2000. Reservoir model of ebb-tidal shoal evolution and sand bypassing. Journal of Waterway, Port, Coastal, and Ocean Engineering, 126(6): 305313.

Lélis, R.J.F. \& Calliari, L.J. 2004. Historical Shoreline Changes Near Lagoonal and River Stabilized Inlets in Rio Grande do Sul State, Southern Brazil. Journal of Coastal Research, 39: 301-305.

Lima, S.F., Almeida, L.E. \& Toldo Jr., E.E. 2001. Estimativa da capacidade do transporte longitudinal de sedimentos a partir de dados de ondas para a costa do Rio Grande do Sul. Pesquisas em Geociências, 28(2): 99-107.

Lopes, C.G., Zanatta, A., Toldo Jr., E.E. \& Nunes, J.C. 2008. 
Mobilidade de curto prazo da linha de praia do litoral norte e médio do RS. In: CONGRESSO BRASILEIRO DE GEOLOGIA, 44., 2008, Curitiba. Anais... Curitiba, ABG, v.1, p. 5.

Motta, L.M. 2011. Balanço de sedimentos arenosos no litoral médio do Rio Grande do Sul. Porto Alegre, 66p. Monografia de Conclusão de Curso, Curso de Geologia, Instituto de Geociências, Universidade Federal do Rio Grande do Sul.

Motta, V.F. 1965. Relatório geral sobre o estudo em modelo reduzido para a regularização da desembocadura do rio Tramandaí. Porto Alegre, Instituto de Pesquisas Hidráulicas, UFRGS, 70p. (Relatório Interno).

Motta, V.F. 1967. Estudo em modelo reduzido para a regularização da desembocadura lagunar de Tramandaí/Rio Grande do Sul. Rio de Janeiro, 69p. (Relatório Interno).

Nimer, E. 1977. Região sul: clima. In: IBGE (Ed.). Geografia do Brasil. Rio de Janeiro, IBGE, p. 35-79.

O’Brien, M.P. 1969. Equilibrium flow areas of inlets on sandy coasts. Journal of Waterways, Harbors and Coastal Engineering Division, 43-52.

Piérri, G.C.S. 2005. Variabilidade da desembocadura do Rio Itapocú: Análise e evolução morfológica em escalas de médio e curto termo. Itajaí, 84p. Monografia de Conclusão de Curso, Curso de Oceanografia, Universidade do Vale do Itajaí.

Pope, J. 2000. Where and Why Inlet Channels Shoal: A Conceptual Geomorphic Framework. ERDC/CHL CHETN - IV - 1. Vicksburg: U.S. Army Engineer Research and Development Center. 10p.

Schossler, V. 2011. Morfodinâmica da desembocadura da Lagoa do Peixe e da linha de praia adjacente. Porto Alegre, 91p. Dissertação de Mestrado, Programa de Pós-graduação em Geociências, Instituto de Geociências, Universidade Federal do Rio Grande do Sul.

Siegle, E. 1999. Morfodinâmica da desembocadura do Rio Camboriú, Balneário Camboriú, SC. Porto Alegre, 124p. Dissertação de Mestrado, Programa de Pós-graduação em Geociências, Instituto de Geociências, Universidade Federal do Rio Grande do Sul.

Siegle, E., Huntley, D.A. \& Davidson, M.A. 2004. Physical Controls on the Dynamics of Inlet Sandbar Systems. Ocean Dynamics, 54: 360-373.

Soares, S.B. 2005. Avaliação experimental da taxa longitudinal de transporte de sedimentos e sua previsão usando formulações globais na zona de surfe da praia de Camburi, Vitória-ES. Vitória, 113p. Dissertação de Mestrado, Programa de Pós-graduação em Engenharia Ambiental, Universidade Federal do Espírito Santo.

Stive, M. J.F. \& Rakhorst, R.D. 2008. Review of empirical relationships between inlet cross-section and tidal prism. Journal of Water Resources and Environmental Engineering, 23: 89-95.

Strohaecker, T.M. 2007. A urbanização no Litoral Norte do Estado do Rio Grande do Sul: contribuição para a gestão urbana ambiental do município de Capão da Canoa. Porto Alegre, 398p. Dissertação de Mestrado, Programa de Pós-graduação em Geociências, Instituto de Geociências, Universidade Federal do Rio Grande do Sul.

Tabajara, L.L.C.A. 1994. Aspectos Hidrodinâmicos e Sedimentologia do Sistema Lagunar-estuarino de Tramandaí-RS. Porto Alegre, 140p. Dissertação de Mestrado, Programa de Pós-graduação em Geociências, Instituto de Geociências, Universidade Federal do Rio Grande do Sul.

Toldo Jr., E.E., Dillenburg, S.R., Cunha, L.O.B.P., Almeida, L.E.S.B., Tabajara, L.L. \& Martins, L.R. 1993. Parâmetros Morfodinâmico da Praia de Imbé, RS, Revista PESQUISAS, 19: 27-32.

Toldo Jr., E.E., Almeida, L.E.S.B., Barros, C. \& Martins, L.R. 1999. Retreat of the Rio Grande do Sul Coastal Zone, Brazil. In: Martins, L.R \& Santana, C.I (Eds.). Non Living Resources of the Southern Brazilian Coastal Zone and Continental Margin. Porto Alegre, Brazil, Editora UFRGS, p. 62-68.

Toldo Jr., E.E., Nicolodi, J.L., Almeida, L.E.S.B. \& Corrêa, I.C.S. 2006. Coastal Dunes and Shoreface Width as a Function of Longshore Transport. Journal of Coastal Research, 39: 390-394.

Tomazelli, L. J. \& Villwock, J.A. 1992. Considerações sobre o ambiente praial e a deriva litorânea de sedimentos ao longo do litoral norte do Rio Grande do Sul, Brasil. Pesquisas em Geociências, 19(1): 3-12.

Travessas, F.A., Dillenburg, S.R. \& Clerot, L.C.P. 2005. Estratigrafia e evolução da barreira holocênica do Rio Grande do Sul no trecho Tramandaí-Cidreira. Boletim Paranaense de Geociências, 57: 57-73.

U.S. Army. 1984. Shore Protection Manual. (4ed.), V.(1). Waterways Experiment Station, Corps of Engineers. USA. 208p.

U.S. Army. 2002. Coastal Engineering Manual. Engineer Manual 1110-2-1100, (1ed). U.S. Army Corps of Engineers, Washington, D.C.

Vieira da Silva, G., Carvalho, J.L.B. \& Klein, A.H.F. 2011. Camacho inlet southern Brazil Instability causes and user conflicts. Ocean \& Coastal Management, 54(8): 569-576.

Weschenfelder, J. \& Ayup-Zouain, R.N. 2002. Variabilidade morfodinâmica das praias oceânicas entre Imbé e Arroio do Sal, RS, Brasil. Pesquisas em Geociências, 29(1): 3-13.
Manuscrito 604

Editores: Maria Luiza C. Rosa \& Paulo A. Souza. 